\title{
PERFIL DOS EGRESSOS DO CURSO DE BIBLIOTECONOMIA DA UNIVERSIDADE FEDERAL DE PERNAMBUCO (2005 A 2010)
}

Resumo: O estudo apresenta o perfil dos egressos do curso de Biblioteconomia da Universidade Federal do Pernambuco (UFPE), no período de 2005 a 2010, vislumbrando a inserção e a tendência desses profissionais formados no mercado de trabalho. Trata-se de uma pesquisa exploratória, cujos dados foram analisados de forma quali e quantitativa, utilizandose de questionário encaminhado ao pesquisado. Os resultados revelaram que no perfil dos egressos da UFPE a maioria é do sexo feminino, atuantes na Região Metropolitana do Recife e que procuraram o curso na busca de conhecimentos específicos e melhores oportunidades no mercado de trabalho.

Palavras-chave: Redes Sociais. Fluxos de Informação. Ciência da Informação.

Abstract: The study presents the profile of the students of the Librarianship course from the Federal University of Pernambuco (UFPE) in the period from 2005 to 2010, seeing the insertion and the tendency of these graduates in the labor market. This is an exploratory study, whose data were analyzed qualitatively and quantitatively, using a questionnaire sent to the researched. The results revealed that the profile of the graduates of UFPE most are female, working in the Metropolitan Region of Recife and sought to travel in search of specific knowledge and better opportunities in the labor market.

Keywords: Graduates. Librarianship. Professional Profile. UFPE.

\footnotetext{
${ }^{1}$ Bacharel em Biblioteconomia pela Universidade Federal de Pernambuco. Universidade Federal de Pernambuco. Brasil. E-mail: charlene.ufpe@gmail.com

${ }^{2}$ Professor Adjunto do Departamento de Ciência da Informação, com atuação nos cursos de Graduação em Biblioteconomia, em Gestão da Informação e no Programa de Pós-Graduação em Ciência da Informação (Mestrado Acadêmico) da Universidade Federal de Pernambuco. E-mail:

fabiopinho@ufpe.br

${ }^{3}$ Professor Assistente vinculado ao Departamento de Ciência da Informação da Universidade Federal de Pernambuco (UFPE). Brasil. E-mail: aw.azevedo@yahoo.com.br

Enviado em: 28/10/2012 - Aceito em: 24/04/2013.
} 


\section{INTRODUÇÃO}

Com as tecnologias da informação e da comunicação regulamentando novos cenários de atuação do profissional da informação no âmbito do mercado de trabalho, tornou-se fundamental uma atitude das Instituições de Ensino Superior (IES) no que concerne a avaliação de seus cursos, para averiguar a aplicabilidade do conhecimento gerado na universidade. Neste cenário, enquadram-se os cursos de Biblioteconomia e Ciência da Informação, onde tal reflexão tem levado seus coordenadores e professores a discutirem sobre a atuação profissional de seus alunos egressos.

O profissional da informação dentro desse contexto tem, muitas vezes, de se ajustar às novas exigências do mercado. Essa adequação passa também pelo entendimento da evolução, da estruturação e da correlação de domínio e interdependência entre o Estado constituído - tanto nacional como internacionalmente - e as profissões que dele fazem parte intrinsecamente.

A preocupação com os rumos da formação do bibliotecário não é recente, portanto não pode ser vista com negligência, visto que, segundo Cunha (2000) e Valentim $(2000 ; 2002)$ a formação profissional está sendo pressionada por novos conceitos, desafios e perspectivas na prática profissional, que envolve a busca pelo aprimoramento contínuo e a observação de padrões éticos de conduta junto às instituições e aos serviços que demandam intervenções de natureza e alcance variados, tais como as bibliotecas, os centros de documentação ou informação, os centros culturais etc.

Diante das mudanças no âmbito do trabalho e também do próprio ensino, as Instituições de Ensino Superior procuram aprimorar seus Planos Políticos Pedagógicos para alcançar melhores resultados no que concerne a avaliação de seus cursos, para averiguar a aplicabilidade do conhecimento gerado na universidade e tornar seus egressos empregáveis. Essa não é uma responsabilidade apenas das instituições, mas também um empreendimento dos discentes, dos egressos e dos órgãos de classe.

Esse fator se reflete no atual momento do mercado do trabalho que exige alta qualificação, articulação de conhecimento e capacidade de adaptar-se. Como profissionais inseridos nesse contexto, os bibliotecários devem compreender as 
exigências do mercado de trabalho, e o meio acadêmico também tem que perceber essas qualificações, oferecendo uma educação que os prepare para esses desafios.

Com isso, esse estudo se justifica pela necessidade de avaliação dos cursos de graduação no país, principalmente na Região Nordeste do País, que apesar da grande oferta de cursos de Biblioteconomia (dez cursos para nove estados), o mercado de trabalho se mostra menor em relação às demais regiões brasileiras, pois a avaliação do curso suscita uma reflexão para o seu aperfeiçoamento.

Portanto, este estudo teve como objetivo geral analisar o perfil dos egressos formados pelo curso de Biblioteconomia da Universidade Federal de Pernambuco, no período de 2005 a 2010. Para isso, de forma mais específica, objetivou-se: (a) identificar as características pessoais dos egressos do curso no período de 2005 a 2010; (b) verificar a atividade profissional desses egressos; e, (c) identificar as relações desses egressos com a instituição que os formou.

\section{FORMAÇÃO DO BIBLIOTECÁRIO NO BRASIL: DESAFIOS E PERSPECTIVAS}

A atuação profissional do bibliotecário foi, ao longo dos séculos, caracterizado como sendo um ato de "zelo" pelos livros, no qual só intelectuais com capacidade de organização e devoção pelos livros podiam realizar. A partir do século XIX, as funções relacionadas à Biblioteconomia se desenvolveram de fato, uma vez que, eram exigidas por parte dos profissionais que iriam atuar na área, técnicas e práticas adequadas para tornar sistêmicas as informações contidas nos acervos das bibliotecas.

Segundo Castro (2000), a primeira escola de graduação em Biblioteconomia foi fundada em 1911, no Rio de Janeiro com forte influência humanista francesa, tendo como "espelho" de L'École de Chartres (França), sob a liderança da Biblioteca Nacional, durante a gestão de Manoel Cícero Peregrino da Silva.

Posteriormente, em 1929, surgiu, em São Paulo, a segunda escola para formação dos bibliotecários, no Instituto Mackenzie, de influência norte-americana com enfoque tecnicista, diferentemente da escola francesa. Nota-se, então, a evolução de dois padrões diferentes de ensino e formação em Biblioteconomia: o Humanista (francês) e o Pragmático-tecnicista (norte-americano), ambos implementados no século XIX. 
Mueller (1985) divide a Biblioteconomia em 5 fases, tomando por base para a sua teoria os escritos de Fonseca (196-?) que dividiu a história da Biblioteconomia em 3 fases, a saber: (1) 1879 a 1929, período correspondente à liderança da Biblioteca Nacional; (2) 1929 a 1962, mudança do paradigma francês pra o estadunidense; (3) a partir de 1962 com o estabelecimento de um currículo mínimo.

Além dessas fases foram acrescentadas por Mueller (1985) duas ações marcantes na consolidação Biblioteconomia no Brasil: (4) década de 70 caracterizada pelo fortalecimento e proliferação dos cursos de graduação e pelo aparecimento das pós-graduações; (5) começando em 1982 com a reformulação dos programas de ensino a partir da aprovação de um novo currículo mínimo.

Sob esse aspecto, Souza (1993, p. 13) reflete que, quando o ensino da Biblioteconomia foi estabelecido no Brasil, ele era utilizado "[...] como arma para promover o deleite da elite e corroborar com a ilustração dessa elite com o mundo civilizado europeu e norte-americano".

Entretanto, com as mudanças ocorridas na última metade do século $\mathrm{XX}$, com fortes influências da globalização e dos avanços científicos e tecnológicos, os profissionais das áreas relacionadas à informação e todos os demais trabalhadores foram afetados. Nessa perspectiva, Arruda, Marteleto e Souza (2000, p. 15) afirmam que, "[...] a demanda por um novo perfil profissional não é exclusiva da área de informação, mas se insere e se articula com as mudanças introduzidas no mundo do trabalho e na demanda do setor produtivo por um trabalhador mais qualificado".

Uma das consequências dessas mudanças está relacionada ao rápido desenvolvimento tecnológico, ocorrido após a Segunda Guerra Mundial. Além disso, o processo de globalização desencadeou uma integração contínua da economia global, impactando vários setores da vida econômica e social dos países, das instituições, das empresas e dos indivíduos, bem como, o aparecimento de novos mercados e oportunidades. Os resultados no setor produtivo foram inúmeros, benéficos ou não, que os levaram a buscar profissionais que tenham formação específica e competências (conhecimento, habilidades e atitudes) que estivessem inseridas na chamada sociedade da informação e do conhecimento.

Nesse aspecto, Valentim (2000, p. 146) relata que, "no terceiro milênio o profissional da informação deverá ser mais observador, empreendedor, atuante, 
flexível, ousado, integrador, pró-ativo e, principalmente, mais voltado para o futuro". Com isso, entende-se que a formação, portanto, deve estar direcionada para a obtenção dessas características. Para tanto o bibliotecário deverá possuir uma melhor qualificação, um envolvimento e participação social mais abrangente e capacidade de trabalhar em equipes inter, multi ou transdisciplinares (BAPTISTA, 2002).

Se, inicialmente, o bibliotecário tinha uma formação voltada à preservação da cultura humana, ao apoio à educação como suporte ao processo de ensino e aprendizagem na parte relativa ao conteúdo para o estudo e à pesquisa, e ao planejamento e à administração de recursos informacionais (MUELLER, 1989), atualmente, a sua formação parte de um núcleo curricular mais amplo como relata Baptista (2002, p. 2), voltada a um perfil generalista com o desafio de prosseguir em um processo de educação continuada mediante as exigências provindas de mutações rápidas e de interesse do mercado.

Por esses motivos, as Instituições de Ensino Superior devem estar atentas aos perfis curriculares previstos em seus cursos de graduação, pois o tripé ensinopesquisa-extensão aliado às opiniões dos egressos configuram-se em um interessante esboço para que os núcleos docentes estruturantes possam iniciar uma avaliação.

\section{O CORPUS DA PESQUISA}

O curso de bacharelado em Biblioteconomia, vinculado ao Departamento de Ciência da Informação (DCI), da Universidade Federal de Pernambuco (UFPE) possui do ano de 1949 até o ano de 2010 um total de 1432 alunos egressos formados. A população-alvo do estudo foi constituída por egressos do período de 2005 a 2010, ou seja, 148 alunos egressos formados.

$\mathrm{Na}$ tentativa de investigar o perfil dos egressos formados pelo curso de Biblioteconomia da UFPE, foi realizado um levantamento nos arquivos do Colegiado do Curso de Biblioteconomia e em atas de colação de grau do Departamento de Ciência da Informação da UFPE, na qual foram encontrados 148 egressos aptos a participarem da pesquisa. Diante disso, o contato com os pesquisados foi realizado através de emails obtidos em listas do Conselho Regional de Biblioteconomia $4^{\mathrm{a}}$ Região (CRB-4) e do cadastro de egressos do DCI. 
Para a coleta de dados aplicou-se um questionário com questões abertas e fechadas. O questionário abrangeu características do perfil desses egressos, atividade profissional, educação continuada e relação com a instituição que o formou.

\section{RESULTADO}

A análise e os resultados dos dados foram desenvolvidos com base nas questões do questionário que foi enviado para todos 148 participantes do estudo. No total foram 77 participantes $(52,02 \%)$ que responderam aos questionários. Esse montante foi suficiente para termos uma amostragem significativa do estudo.

Com base na tabulação dos dados coletados, as tabelas e gráficos a seguir expõem a reunião dos resultados impetrados com a aplicação do questionário. As respostas permitiram o conhecimento de informações relevantes em que os percentuais obtidos traduzem o perfil dos egressos do curso de Biblioteconomia da UFPE. Por isso, as questões foram divididas em grupos conforme o assunto, resultando na seguinte classificação: características pessoais, atividade profissional e relação dos ex-alunos com a UFPE.

\section{Características Pessoais}

O perfil dos egressos estudados reflete profissionais dos quais $71 \%$ são do sexo feminino e $27 \%$ são do sexo masculino, com idades entre 22 a 49 anos, estudando em média 4 anos no curso.

Sobre esse aspecto, os estudos de Cunha (2004) mostram a tendência da Biblioteconomia ser uma área do conhecimento com predominância do sexo feminino, o que, de certa forma, confirma-se nesta pesquisa. Já a questão sobre a idade dos participantes elucidou que a idade média do egresso do curso é de 29 anos. Infelizmente, a maneira como os dados foram coletados não permitiu o conhecimento da média e da mediana da idade por gênero.

\section{Atividade Profissional}

No âmbito da atividade profissional, a questão sobre a atividade e capacitação profissional, bem como o local de atuação dos egressos, revelou que uma pequena parcela deles respondeu que ainda não exerceu atividade profissional depois de 
formado (8\%). Esse dado revela que a maioria dos egressos (91\%), que respondeu ao questionário, obteve um alto índice de empregabilidade.

Logo em seguida, questionados se estavam exercendo a profissão relacionada à Biblioteconomia, a maioria dos pesquisados $(90 \%)$ respondeu que está trabalhando com atividades na área, o que sugere que os egressos do curso não abandonaram a área de formação.

Em decorrência disso, os pesquisados foram questionados sobre o tipo de instituição na qual atuavam e a maioria dos respondentes (60\%) apontou que trabalha na esfera pública, mostrando que a instituição pública é um empregador de destaque. Já a instituição privada, que ainda é um empregador modesto, correspondeu a $26 \%$ das respostas. A atuação em outros tipos de organizações soma $14 \%$ dos respondentes.

Em relação a função ou cargo exercido, a análise objetivou comprovar o uso da nomenclatura "Bibliotecário(a)" para a profissão no mercado de trabalho, fato que foi evidenciado com $50 \%$ das respostas positivas ao termo. Esse alto índice também está relacionado ao fato de que a nomenclatura "Bibliotecário", além de ser uma profissão reconhecida e regulamentada, está inserida na Classificação Brasileira de Ocupações (CBO). Além disso, as outras denominações também fizeram alusão ou incluíram a palavra 'bibliotecário'.

Figura 1 - Função ou cargo exercido

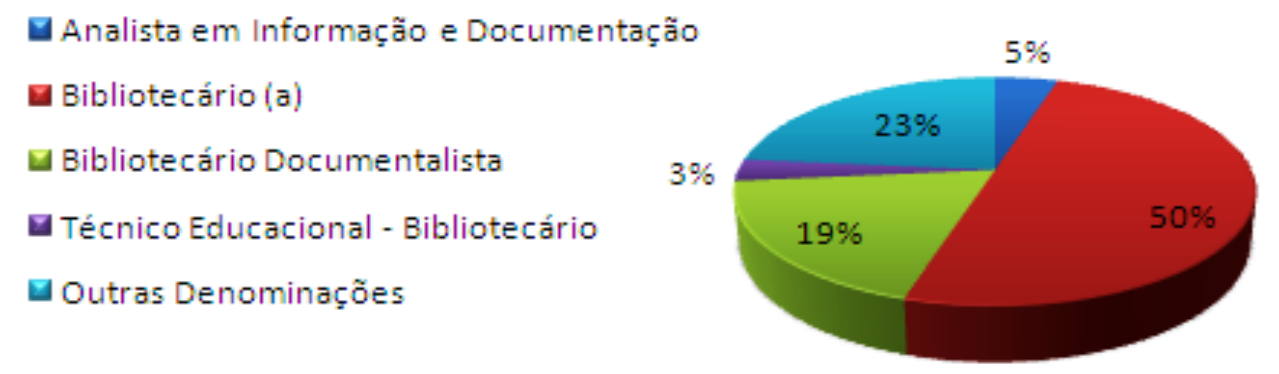

Fonte: Elaborado pelos autores

A média da faixa salarial percebida pelos egressos pesquisados está entre $R \$$ 1.000,00 a R \$ 5.000,00, ou seja, uma média de nove salários míninos atuais ${ }^{4}$. Em comparação aos dados levantados por Fonseca (2008) percebe-se que o salário no

${ }^{4}$ Salário mínimo de $\mathrm{R} \$ 545,00$, em 2011.

\begin{tabular}{l|l|l|l|l|l|l}
\hline (C) Rev. digit. bibliotecon. cienc. inf. & Campinas, SP & v.11 & n.2 & p.222-236 & maio/ago. 2013 & ISSN 1678-765X \\
\hline
\end{tabular} 
setor público para o bibliotecário na Região Nordeste do País mantém índices semelhantes ao ano de 2008 em relação a sua média.

Os egressos também foram questionados sobre a região em que atuavam, uma vez que esse fator tem relação com a faixa salarial percebida. Dessa forma, percebeuse uma maior incidência da Região Metropolitana do Recife (74\%), porém alguns desses profissionais têm atuado no interior do Estado de Pernambuco (14\%) e também fora dele (12\%). É importante salientar que até o momento não existe no Estado outra escola de Biblioteconomia que não seja a da UFPE. De certa forma, parece curioso notar que a atuação dos egressos no interior do Estado é menor, pois se trata de uma região com muitas cidades que possuem bibliotecas públicas, escolares e universitárias. Contudo não se pode ignorar outras variáveis como o cargo disponível, o salário e as condições de trabalho.

Um dado interessante sobre a inserção do egresso e o exercício de sua atividade profissional, refere-se ao fato de que $51 \%$ dos respondentes começaram a exercer sua atividade em menos de um ano após a conclusão do curso. Outro resultado interessante está no fato de que 30\% dos egressos já trabalhavam na área. Os demais índices giram em torno de 2 a 4 anos para o início das atividades bibliotecárias.

Nesse sentido, buscou-se também identificar se egressos possuem interesse na educação continuada. Os resultados demonstraram que $75 \%$ dos egressos já realizaram ou estão realizando cursos de pós-graduação.

Por isso, de maneira a complementar a questão sobre a educação continuada, eles foram questionados sobre o nível da pós-graduação. As respostas revelaram que $70 \%$ dos respondentes assinalaram que cursam ou já cursaram especialização lato sensu e $2 \%$ cursam ou já cursaram um mestrado profissional. Esse índice demonstra a procura por cursos dessa natureza que capacitam para o mercado de trabalho. Interessante notar também que $28 \%$ dos respondentes estão interessados na carreira acadêmica, ou seja, em formar os futuros profissionais e, por isso, buscaram cursos strictu sensu de caráter acadêmico.

Em relação à questão da instituição em que fez ou faz a pós-graduação, considerando a última titulação, a figura 2 demonstra as instituições onde os egressos foram buscar suas capacitações no âmbito da pós-graduação. O resultado mostra que 
36\% escolheram a UFPE para prosseguir os estudos em nível de pós-graduação. Esses dados podem subsidiar futuros cursos de pós-graduação nas instituições de ensino em Biblioteconomia.

Figura 2 - Instituição em que realiza(ou) a pós-graduação, de acordo com a última titulação.

$\begin{array}{lll}\square \text { UFPE } & \square \text { FSH } & \text { Prominas- Finom } \\ \text { UUNICAP } & \square \text { FAFIRE } & \square \text { SENAC } \\ \text { MALUBCarpina-PE } & \square \text { IBPEX Facinter } & \square \text { FADEPE } \\ \square \text { UNIVERSO } & \square \text { FCAP } & \square \text { Faculdade Joaquim Nabuco } \\ \square \text { Esuda } & \square \text { FIJ-EAD } & \square \text { UFPB } \\ \square \text { UFJF } & \square \text { PUCCAMP } & \square \text { Não citaram a instituição }\end{array}$

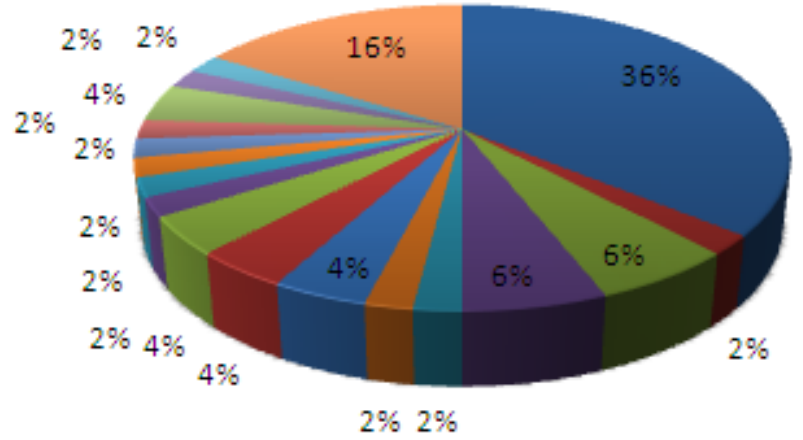

Fonte: Elaborado pelos autores

\section{Relação dos Ex-Alunos com a UFPE}

Sobre a relação que o egresso mantém com a instituição que o formou, a pesquisa demonstrou que 15\% mantêm um vínculo com a UFPE por causa das atividades profissionais, indo a Universidade frequentemente. Essa frequência referese às atividades de participações em eventos (16\%). Por outro lado, 22\% dos entrevistados não mantêm contato com a instituição de ensino, conforme demonstra o quadro 1 a seguir. 


\section{PESQUISA}

Quadro 1 - Contato com a UFPE.

\begin{tabular}{|c|c|c|c|c|}
\hline & Frequentemente & Esporadicamente & Raramente & $\begin{array}{l}\text { Não tenho } \\
\text { contato }\end{array}$ \\
\hline $\begin{array}{l}\text { Vínculo empregatício } \\
\text { com a UFPE }\end{array}$ & $15 \%$ & $1 \%$ & $1 \%$ & $71 \%$ \\
\hline $\begin{array}{l}\text { Participação em } \\
\text { eventos (palestras, } \\
\text { seminários, workshops, } \\
\text { jornadas, congressos) }\end{array}$ & $16 \%$ & $23 \%$ & $34 \%$ & $22 \%$ \\
\hline $\begin{array}{l}\text { Atividades de extensão } \\
\text { oferecidas pela UFPE }\end{array}$ & $10 \%$ & $13 \%$ & $23 \%$ & $48 \%$ \\
\hline $\begin{array}{l}\text { Procura dos serviços } \\
\text { prestados pela UFPE } \\
\text { (biblioteca, laudos } \\
\text { técnicos, lazer etc.) }\end{array}$ & $20 \%$ & $24 \%$ & $22 \%$ & $28 \%$ \\
\hline $\begin{array}{l}\text { Providenciar } \\
\text { documentos } \\
\text { acadêmicos }\end{array}$ & $9 \%$ & $28 \%$ & $41 \%$ & $15 \%$ \\
\hline
\end{tabular}

Fonte: Elaborado pelos autores.

Para as atividades de extensão oferecidas pela UFPE, no que concerne àquelas que não sejam eventos científicos, o resultado mostrou um índice muito baixo de egressos nesse tipo de atividade, ou seja, $48 \%$ dizem não ter contato com a instituição de ensino e somente $10 \%$ participaram de atividades dessa natureza frequentemente. Em relação à procura dos serviços prestados pela UFPE, os resultados sugerem uma boa distribuição entre as alternativas, pois todas as respostas estão numa média de 20\%. Em relação a providência de documentos acadêmicos, o resultado mostrou que a maioria dos egressos $(41 \%)$ não procura a universidade para tal fim.

A relação que o egresso mantém com a universidade pode revelar outros aspectos intrínsecos da formação do egresso. Por conta disso, ele foi questionado sobre a articulação entre teoria e prática. Dessa maneira, foi possível observar que $70 \%$ dos pesquisados indicaram a falta de articulação entre teoria e prática. Obviamente que essa articulação depende de diversos fatores como estágio, grupo 
PET, iniciação científica, extensão entre outros. No que tange a essa pesquisa, essa questão refletiu quando o entrevistado foi questionado sobre suas expectativas quanto à formação profissional. Os resultados mostraram que $47 \%$ dos pesquisados afirmam que o curso atendeu medianamente a sua expectativa e $44 \%$ afirmam que o curso atendeu as suas expectativas.

Em relação ao estágio curricular, 26\% dos egressos consideraram que ele contribuiu significativamente para a sua formação.

Figura 3 - Expectativa em relação ao estágio curricular.

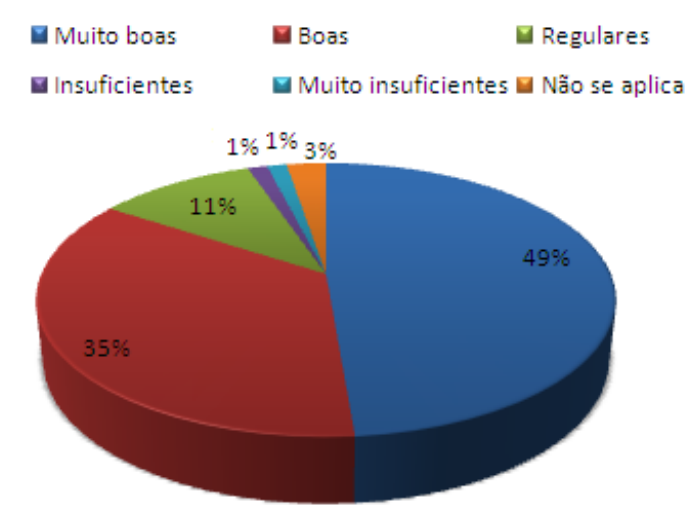

Fonte: Elaborado pelos autores.

Os resultados da Figura 3 sugerem que a maioria dos egressos (49\%) considera que as condições de acesso aos estágios curriculares foram muito boas, $35 \%$ dos pesquisados, por sua vez, consideraram boas as condições de acesso e, por fim, $11 \%$ consideraram regulares. As outras condições somam $5 \%$.

Sobre as atividades de pesquisa, percebeu-se que $50 \%$ dos sujeitos participaram ocasionalmente de projetos dessa natureza, ao passo que $29 \%$ responderam que nunca participaram de projetos de pesquisa. Esse resultado demonstra um nível significativo de alunos dedicados à pesquisa no curso.

Em relação às atividades de extensão percebeu-se que $43 \%$ dos sujeitos da pesquisa participaram ocasionalmente de projetos dessa natureza e $41 \%$ responderam que nunca participaram de projetos dessa natureza.

$\mathrm{Na}$ questão sobre a produção acadêmica, ou seja, se o egresso produziu ou colaborou com algum trabalho científico tais como artigos para revistas ou eventos científicos, os resultados revelaram que 53\% dos formados produziram ou 
colaboraram com algum trabalho científico, demonstrando que o incentivo desse tipo de atividade.

A pesquisa também procurou observar a avaliação dos egressos referentes ao conjunto das condições didático-pedagógicas dos professores durante o curso. De acordo com resultados obtidos os egressos julgaram como sendo "muito bom" o relacionamento dos professores com os estudantes (62\%). Em relação ao domínio de conteúdo, os egressos o julgaram como insuficiente (22\%). Sobre os procedimentos metodológicos empregados, os resultados demonstraram o mesmo índice de 54\% entre regular e muito insuficiente. As questões sobre assiduidade e pontualidade e sistemas de avaliação obtiveram um grande número de abstenções (27\%) e (10\%), respectivamente.

Nesse sentido, perguntou-se também o grau de satisfação com curso e as respostas indicaram que $73 \%$ dos sujeitos da pesquisa estão satisfeitos com o curso, ao passo que $21 \%$ estão insatisfeitos e $6 \%$ afirmam que estão muito satisfeitos. O grande número de respostas positivas demonstrou certa disparidade entre as respostas da questão anterior, já que os mesmos não se mostram satisfeitos com as condições didático-pedagógicas oferecidas, sendo este um assunto que contribui significativamente para o nível de satisfação da população estudada.

No que tange à infraestrutura das bibliotecas da UFPE, 64\% dos egressos julgaram-nas parcialmente adequadas, 27\% afirmaram que elas são adequadas, 8\% avaliaram-nas como sendo inadequadas e somente $1 \%$ assentiram que elas são muito adequadas. O resultado mostra que as bibliotecas da UFPE precisam melhorar sua infraestrutura para oferecer um serviço adequado aos alunos.

$\mathrm{Na}$ sequência, foi solicitado aos pesquisadores que avaliassem os serviços oferecidos pela universidade quando os egressos ainda estudavam e os resultados foram sistematizados no quadro a seguir. 
Quadro 2 - Avaliação dos serviços oferecidos pela UFPE.

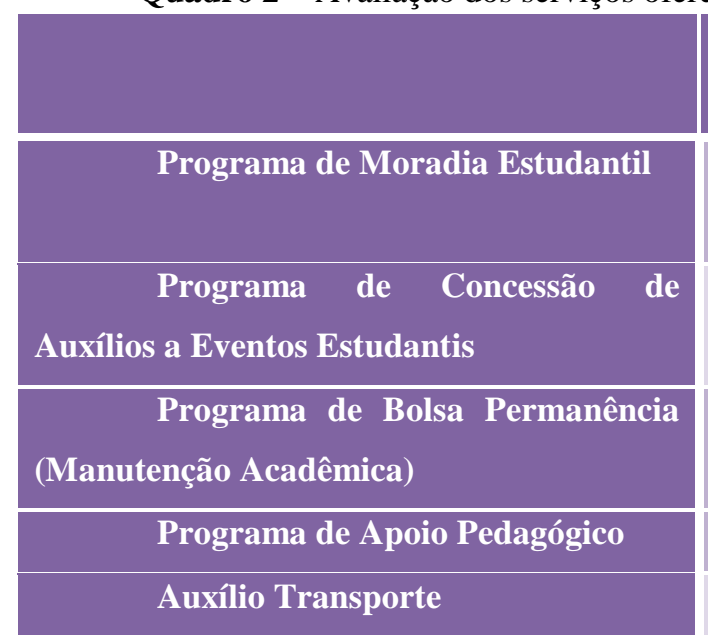

\begin{tabular}{|r|r|r|}
\hline Satisfatório & Insatisfatório & \multicolumn{2}{|l|}{$\begin{array}{l}\text { Desconheço } \\
\text { serviço }\end{array}$} \\
\hline $11 \%$ & $14 \%$ & $65 \%$ \\
\hline $24 \%$ & $16 \%$ & $51 \%$ \\
\hline $20 \%$ & $16 \%$ & $57 \%$ \\
\hline $6 \%$ & $11 \%$ & $75 \%$ \\
\hline $5 \%$ & $11 \%$ & $75 \%$ \\
\hline
\end{tabular}

Fonte: Elaborado pelos autores.

As respostas sugerem que a maioria dos egressos desconhece os serviços oferecidos pela Universidade, já que em todas as questões a alternativa "Desconheço o serviço" atingiu mais de $50 \%$.

\section{CONSIDERAÇÕES FINAIS}

Possuir um Plano Político Pedagógico atual e contemporâneo é o objetivo de muitas coordenações de curso e de núcleos docentes estruturantes. Além disso, os atuais indicadores de avaliação dos órgãos reguladores refletem a busca pela excelência no ensino. Dessa forma, muitas Instituições de Ensino Superior buscam atualizar seus currículos, o que é o caso da Universidade Federal de Pernambuco, além de muitas outras. Aliado a esses fatores tem-se a necessidade de conhecer o egresso e sua atuação no mercado de trabalho.

Esta pesquisa se insere nessa necessidade e, por isso, foi sistematizada para subsidiar e auxiliar nas decisões de atualização do currículo do curso de Biblioteconomia da UFPE. Nesse sentido, as considerações que aqui se tecem não possuem características generalizantes pela própria natureza da pesquisa. Nesse sentido, alguns pontos chamam a atenção, tais como: a maioria dos egressos da Universidade Federal de Pernambuco no seu curso de Biblioteconomia é do sexo feminino, atuando na e em plena carreira profissional, com a faixa média de idade de vinte e nove (29) anos, trabalhando em sua maioria, na Região Metropolitana de 
Recife com um mercado de trabalho que possuiu um alto grau de empregabilidade, tendo como o seu maior empregador, na região do Nordeste, o setor público.

É necessário salientar que o período que compreende a pesquisa foi contemplado por diversos concursos públicos e esse fator pode ter vindo a influenciar na empregabilidade dos egressos. A maioria dos respondentes iniciou suas atividades em menos de um ano após a conclusão do curso, percebendo um aumento no interesse pelos cursos de pós-graduação, tanto por aqueles que capacitam para o mercado de trabalho quanto para a carreira acadêmica.

Na prática de atividades complementares a sua formação, a participação em eventos e os estágios obtiveram predominância, pois ampliou o conhecimento e permitiram a experiência prática, respectivamente. Os pesquisados se mostraram satisfeitos com o curso, porém se demonstraram insatisfeitos com a articulação entre teoria e prática.

Por fim, cabe salientar que a pesquisa obteve êxito em relação aos objetivos elencados para a sua execução, no sentido de conhecer o perfil do estudante egresso e sua atuação profissional.

\section{REFERÊNCIAS}

ARRUDA, M. C. C.; MARTELETO, R. M.; SOUZA, D. B. de. Educação, trabalho e o delineamento de novos perfis profissionais: o bibliotecário em questão. Ciência da Informação, Brasília, v. 29, n. 3, p. 14-24, set./dez. 2000. Disponível em: <http://www.scielo.br/pdf/ci/v29n3/a02v29n3.pdf>. Acesso em: 12 abr. 2010.

BAPTISTA, S. G. Habilidades necessárias para o profissional atuar na era da informação: uma reflexão sobre as tendências do mercado. In: Congresso de Biblioteconomia e Documentação e Ciência da Informação, 20., 2002. Anais eletrônicos. Fortaleza: ABC, 2002.

CASTRO, C. A. História da biblioteconomia brasileira: perspectiva histórica. Brasília: Thesaurus, 2000. 288 p. 
CUNHA, M. V. da. O profissional da informação e o mercado de trabalho. Informação e Sociedade: estudos, João Pessoa, v. 10, n. 1, p. 159-167, jan./jun. 2000.

CUNHA, M. V. da et al. O bibliotecário formado pela Universidade Federal de Santa Catarina: perfil profissional. Perspectivas em Ciência da Informação, Belo Horizonte, v. 9, n. 2, p. 182-195, jul./dez. 2004. Disponível em:

<http://portaldeperiodicos.eci.ufmg.br/index.php/pci/article/view/359> Acesso em: 02 nov. 2011

FONSECA, L. G. Remuneração dos concursos em biblioteconomia. 2008. Disponível em: <http://www.biblioconcursos.com.br/remuneracao.html>. Acesso em: 20 nov. 2011.

MUELLER, S. P. M. O ensino de biblioteconomia no Brasil. Ciência da Informação, Brasília, v. 14, n. 1, p. 3-15, jan./jun. 1985.

MUELLER, S. P. M. Perfil do bibliotecário, serviços e responsabilidades na área de informação e formação profissional. Revista de Biblioteconomia de Brasília, Brasília, v. 17, n. 1, p. 63-70, jan./jun. 1989.

SOUZA, F. C. de. Biblioteconomia no Brasil: profissão e educação. Florianópolis: Associação Catarinense de Bibliotecários, 1993. 142 p.

VALENTIM, M. L. P. Atuação e perspectivas profissionais para o profissional da informação. In: (Org.). O profissional da informação: formação, perfil e atuação profissional. São Paulo: Polis, 2000. 156 p. (Palavra-Chave, 11).

VALENTIM, M. L. P. Formação: competências e habilidades do profissional da informação. In: (Org.). Formação do profissional da informação. São Paulo: Polis, 2002. 152p.

(Palavra-Chave, 13).

\section{Como citar este artigo:}

SANTOS, Charlene Maria dos; PINHO, Fabio Assis; AZEVEDO, Alexander Willian. Perfil dos egressos do curso de Biblioteconomia da Universidade Federal de Pernambuco (2005 a 2010). Rev. digit. bibliotecon. cienc. inf., Campinas, SP, v. 11, n. 2, p.222-236, maio/ago. 2013. ISSN 1678-765X. Disponível em: <http://www.sbu.unicamp.br/seer/ojs/index.php/rbci> 